\title{
España y la comunidad judía de Estambul a la luz de las descripciones de viajeros españoles (1784-1907)*
}

Pablo Martín AsUero

Universidad Jules Verne, Beauvais

Tras las paces hispano-turcas de 1783 se abre un período de entendimiento entre el Imperio español y el otomano que perdurará a lo largo de la llamada Cuestión de Oriente (17741923). Fue precisamente la óptica ilustrada de Carlos III y de Floridablanca la que produjo el cambio en la percepción española del Imperio otomano, desde la postura de los Habsburgo en el siglo XVI, enemiga de unos turcos protectores de moriscos y sefardíes, a la de finales del Siglo de las Luces. En este contexto, las memorias de las expediciones fletadas a la Sublime Puerta en las postrimerías del siglo XVIII se acercan bastante a las de tipo enciclopédico, modelo impuesto por Mouradjea d'Ohusson en su Tableau Général de l'Empire Ottoman (París 1789). Así, las obras literarias españolas se basarán en este tipo de narraciones o en textos de literatura de viajeros, en su mayoría de autores franceses.

Uno de los objetivos de la toma de contacto hispano-turca era el de hacerse con representantes para la defensa de los intereses españoles, algo en lo que franceses, italianos, ingleses, rusos o suecos habían tomado la delantera a los españoles. La

* Comunicación presentada al sexto Congreso de la European Association for Jewish Studies (Toledo, 19-23 de jul. de 1998). 
opinión de España se centraba especialmente en los intereses económicos, tal y como afirmaba José Moreno en 1790:

Los armenios, griegos y judíos (linajes despreciados por los turcos) son los dueños del comercio en Turquía. Y esta circunstancia de haber de tratar especialmente con los judíos, obliga siempre a tomar precauciones particulares ${ }^{1}$.

Con los siguientes argumentos ese mismo autor desaconseja emplear a los judíos:

Pero aun cuando sean agentes de los europeos, nunca dejan de atender primero a su provecho, con cuya intención almacenan de todo, bueno y malo, y de ello componen sus remesas. Agregando a las ganancias que este proceder les rinde, las del dos o tres por ciento de comisiones con que prometieron antes contentarse, véanse que fe merecen, y cuál será el beneficio que resulte de establecer factorías nacionales 2

Un viajero español coetáneo, José Solano Ortiz de Rozas, realizó una descripción más completa de la comunidad judía, aportando información sobre su indumentaria, organización y papel en la sociedad otomana. Al igual que Moreno destaca el hecho de que judíos y cristianos tenían un régimen fiscal diferente al de los musulmanes, al basarse estos últimos en los preceptos del Corán. Hay que tener en cuenta que la sociedad otomana clásica estaba estructurada según el sistema de millet 'naciones', que agrupaba a los miembros de un determinado culto, como en el caso de los griegos ortodoxos, armenios de rito gregoriano, católicos o hebreos ${ }^{3}$.

El acercamiento hispano-otomano se interrumpió con la invasión napoleónica de la Península Ibérica y sus posteriores

1 José Moreno, Viaje a Turquía (Madrid 1790) pág. 256.

2 Moreno Turquía pág. 256.

3 Sobre este tema hay una abundante bibliografía. Aparte de las obras que citaré, pueden consultarse Abraham GalanTe, Histoire des Juifs d'Istambul ..., 2 vols. (Estambul 1941-1942; reed. 1987); S. RosAnEs, Korot ha-yehudim beTurquia u-bearsot ha-quédem, 6 vols. (Jerusalen y Sofía 1930-1945); B. LEWIS, Jewish of Islam (Princenton University Press 1984); Naim GÚLERYÚZ, Türk Yahudiler Tarihi: I, 20. yüzyılına kadar (Istambul 1993); Riva KASTORIANO, «Trajectoires dans la ville, les Juifs à Istanbul», Critique (ag.-sept. 1992) págs. 656-670. 
repercusiones. Durante la primera mitad del siglo XIX el interés español se centró al otro lado del Atlántico, donde las colonias iban emancipándose. La Cuestión de Oriente pasó a un segundo plano y tan sólo la firma del Segundo Tratado entre España y Turquía en 1827, coincidiendo además con la Guerra de Independencia Griega, impulsará la aparición de nuevas obras sobre el tema. Tal es el caso de Descripción geográfica, política, militar, civil y religiosa, de Vicente Roger y Coma, o La Turquía, teatro de la guerra presente, de Fermín Caballero. Desgraciadamente esos textos no sólo no aportan nada nuevo sobre el tema de la comunidad judía, sino que el segundo es además un plagio de la de José Moreno, editada cuarenta años antes 4 .

Habrá que esperar a la Guerra de Crimea (1854-1856), durante la cual la tímida participación española en el bando pro-otomano volverá a poner de actualidad la situación del «enfermo de Europa». No hay que olvidar que ciertos escritores franceses (Chateaubriand, Lamartine, Gautier, Nerval o Flaubert) habían puesto de moda el tema del «voyage en Orient» desde una perspectiva claramente romántica. Uno de los pocos textos españoles que se enmarcan en esa corriente es el Viaje a Oriente, de Madrid a Constantinopla, de Adolfo de Mentaberry. Las memorias de este diplomático romántico, destinado primero en Damasco y luego en Estambul, proporcionan un interesante documento de primera mano sobre la Cuestión de Oriente, desvinculado de los moldes de la Ilustración o de la literatura de cautivos de épocas anteriores. Mentaberry es uno de los primeros en informar sobre el origen hispánico de las comunidades judías otomanas, un dato que no estaba presente en los textos de finales del siglo XVIII. Manifiesta su sorpresa al encontrarse con esos «descendientes de aquellos que nuestros Reyes Católicos desterraron» y sobre todo de que «no tienen rencor alguno contra nosotros, nos tratan siempre bien y nos escuchan con palpitante embeleso'» 5. Describe la situa-

4 Ya me he ocupado de ese tema en «Los judíos de Estambul en dos textos de viajeros españoles 1790-1896», Raices 27 (1996) págs. 51-54.

5 Adolfo de Mentaberry, Viaje a Oriente, De Madrid a Constantinopla (Madrid 1873) págs. 123-124. Sobre este autor véase mi artículo «Adolfo de Mentaberry», Escala 3, de próxima aparición. 
ción de los sefardíes de Beirut y se centra en la comunidad de Estambul, donde las reformas del Tanzimat impuestas por los aliados de la Guerra de Crimea iban modernizando la sociedad otomana, afectando sobremanera a la alta burguesía apoyada por las naciones de Europa occidental:

Una turba innumerable de fraques y corbatas blancas bastante mal llevados por hombres jóvenes y viejos, mas vulgares en su gran mayoría, de anchos pies y gruesas manos, algunos con sortijas sobre los guantes y todos con riquísimas cadenas y preciosas botonaduras [...] a la legua se veía en ellos al tendero comisionista $o$ tenedor de libros, al corredor de letras o al negociante; es decir, al hortera pretérito y al futuro banquero, ora fuesen judíos, que es lo general, o bien griegos, levantinos, armenios o europeos ${ }^{6}$.

Mentaberry trata también de la situación de la familia Camondo 7, a cuyo jefe había nombrado conde el rey Víctor Manuel de Italia, y aporta una serie de datos hasta ahora mantenidos en secreto o desconocidos: la existencia de la prensa sefardí y de apellidos sefardíes similares a los españoles; y como lo hiciera en el caso de Beirut, menciona la posesión de llaves o los títulos de las propiedades que dejaron al ser expulsados de España.

En 1871, aprovechando las buenas relaciones entabladas tras la guerra de Crimea entre Europa occidental y el Imperio otomano y el momento de bonanza económica, España envió la fragata Arapiles por el Mediterráneo oriental. La memoria de dicha expedición corrió a cargo de un intelectual de primera fila, Juan de Dios de la Rada y Delgado. Este autor no logra prescindir de sus prejuicios - «raza deicida» les llama-, y a la hora de describir el barrio judío de Balat se sirve de un fragmento de Constantinople de Gautier, conocido por su actitud antisemita 8. De la Rada, como la mayoría de los observadores españoles, mantiene una cierta distancia con respecto a los sefardíes, lo cual no le impide trazar un análisis lingüístico bastante realista:

\footnotetext{
6 Mentaberry Viaje pág. 478.

7 Me ocupo de ello en mi artículo "La Familia Camondo», entregado a Raices.

8 Véase la edición de Jaques Huré (Estambul-París 1990) pág. 212 nota 4.
} 
Los de Constantinopla y demás ciudades del Oriente, que recorrimos en nuestro viaje, hablaban castellano aunque muy italianizado y con giros más propios de los siglos XV y XVI que de las épocas modernas; lo cual tiene fácil explicación por el poco roce que tienen con españoles y las muchas relaciones mercantiles que mantienen con los italianos, de donde ha resultado naturalmente que siendo los dos idiomas tan afines, el castellano de la época de la expulsión que el que aquellos judíos pueden conservar, se haya modificado por la influencia del italiano que están oyendo hablar casi a diario ${ }^{9}$.

De la Rada es uno de los observadores que tiene una percepción más completa de la comunidad judía. Empieza con un comentario de tipo antropológico, refiriéndose a la raza semítica con «caracteres físicos y morales indelebles» ${ }^{10}$, para después pasar a su actividad más interesante: el comercio. Tras esta introducción, de la Rada traza su devenir histórico desde Babilonia hasta finales del siglo XIX, haciendo hincapié en cómo se han apartado los judíos contemporáneos comerciantes de aquellos pastores y agricultores de los tiempos en que vivían en Palestina. Otro aspecto importante es el papel de la educación, aportando datos de 1866: 29 escuelas elementales, 4 superiores y un establecimiento de segunda enseñanza ${ }^{11}$.

Resulta interesante el análisis de de la Rada sobre el papel de los judíos en el seno de la sociedad otomana y su organización interna:

Descendientes en su mayor parte de los judíos españoles, que dejaron su patria en las diversas épocas de la expulsión. Se dividen en dos facciones, o sea los talmudistas y los karaïtas, y tienen la dirección de sus asuntos civiles y religiosos, los rabinos, de los cuales el de Constantinopla, aunque no ejerce ninguna clase de autoridad sobre sus compañeros de otras poblaciones, lleva el nombre de Gran rabino, y goza, con respecto a la sociedad turca, los mismos privilegios que los patriarcas. Tiene como cuerpo consultivo, un consejo compuesto de seis miembros, de los cuales tres son rabinos y tres son laicos. Para los asuntos judiciales hay un tribunal llamado Bet-din, que consta de tres jueces, y para lo que pudiéramos llamar la policía urbana, tienen un magistrado especial

9 Juan de Dios de la Rada Delgado, Viaje a Oriente de la Fragata de Guerra Arapiles (Barcelona 1876) vol. II pág. 236.

10 Rada Delgado Arapiles vol. II pág. 262.

11 Rada Delgado Arapiles vol. II pág. 248. 
al que le dan el nombre español de Regidor. En las capitales de las provincias hay ocho rabinos, que tienen a sus órdenes otros nueve de menor categoría. La comunión israelita paga a unos y a otros, sostiene las sinagogas, y dando un ejemplo de caridad, paga los impuesto de los pobres que no pueden hacerlo ${ }^{12}$.

De la Rada apenas hace mención de los cambios establecidos tras la publicación del decreto Hatti Hümayun en 1856, por el que se anulaba parte de las discriminaciones anteriormente criticadas. Este nuevo decreto enfatizaba de una manera inequívoca la igualdad de todos los súbditos otomanos al margen de las diferencias en lo referente a religión, etnia o idioma. Les colocaba a todos en un mismo nivel en los asuntos de impuestos, servicio militar, educación, justicia, propiedad o eligibilidad para cargos públicos o administrativos ${ }^{13}$.

Esta nueva situación era compatible con la que describe de la Rada, según la cual la comunidad judía mantenía una cierta autonomía al contar con sus propios consejos. Un importante detalle en la opinión del viajero español es el de que el Cuerpo Consultivo estaba compuesto de tres rabinos y tres laicos, lo cual indica el proceso de modernización, equilibrándose el peso específico de los sectores religiosos y no religiosos.

Apenas difieren de la postura oficial descrita por de la Rada las noticias de los diplomáticos o de los viajeros de los últimos años del siglo. Ese es el caso de Melchor Ordóñez Ortega, quien según el modelo de Gautier se limita a describir la suciedad del barrio judío. Se trata de un tema bastante habitual en la literatura de viajeros que tiene en Edmundo d'Amicis (uno de los autores italianos de la segunda mitad del siglo XIX más traducidos y difundidos en España) su más claro exponente:

En todas partes se veían chicuelos cubiertos de costuras y lamparones que se revolcaban por el suelo; viejas desastradas y repugnantes que con la descarnada mano trabajaban en los portales de las casas, llenas de harapos y hierro viejo; hombres envueltos en luengos vestidos sucios, con un pañizuelo ceñido a la cabeza, que con ademán furtivo se deslizaban a lo largo de las paredes; rostros

12 Rada Delgado Arapiles vol. II pág. 233.

13 Salâhi R. Sonyel, Minorities and the Destruction of the Ottoman Empire (Ankara 1993) pág. 149. Véase Gülnihâl BozTúRK, Gayrimüslim Osmanlı Vatandaslarını Hukukî Durumu ['Situación legal de los no-musulmanes en la ciudadanía otomana'] (Ankara 1989). 
macilentos en las ventanas, andrajos colgando entre casa y casa, cieno y ruinas en todas partes. Es Haskioi, el arrabal israelita, el ghetto de la orilla septentrional del Cuerno de Oro ${ }^{14}$.

Si se yuxtaponen las imágenes creadas por la literatura de viajeros, bien sean nacionales o traducciones, con las de las memorias de las expediciones se logra un retrato bastante completo de la situación de los judíos en la capital del Imperio otomano, el cual abarca desde las clases sociales más desfavorecidas hasta la próspera burguesía de banqueros y comerciantes. Todas esas noticias, de escasa incidencia en España, se fueron espaciando a lo largo de la Cuestión de Oriente y será la campaña del doctor Pulido la que de nuevo sacará a la luz a los sefardíes otomanos.

Uno de los precedentes de Pulido fue Alfredo Opisso, cuyas obras de carácter enciclopédico le dieron un cierto renombre. En Turquía y los Estados Danubianos (1896) narra el viaje de Federico Morales Peñalba, un filólogo valenciano, a Rumania con escala en Estambul. La capital otomana le proporciona la posibilidad de entrar en contacto con la realidad sefardí:

Sépase, pues, que Abraham Antequera, -Abraham Antequera, así como suena-, era redactor del periódico tri-semanal El Telégrafo, así como suena también: en castellano, político, científico y literario, redactado en la lengua de Arias Montano, aunque impreso en caracteres hebraicos, con las oficinas en Gálata. Pero no paró allí el asombro de nuestro filólogo sino que subió de punto cuando Abraham Antequera, le dijo que también se publicaba en Constantinopla otro periódico en castellano, El Tiempo, bi-semanal, cuyas oficinas estaban también en Gálata.

Jamás en sus días hubiera podido creer D. Federico que se publicaran en Constantinopla dos periódicos en castellano. Ni que hubiera allí algunos millares de habitantes que no hablaran otra lengua en el hogar doméstico [...] ${ }^{15}$.

14 Edmundo d'Amicis, Constantinopla ( $1^{\circ}$ ed. Milán 1879); publicado en español por entregas en El Mundo Ilustrado (Ed. Espasa: Barcelona 1881) tomo I, $2^{\text {a }}$ serie, pág. 166 (reed. 1895); otra versión de V. SuÁrez (Madrid 1883).

15 Alfredo OpIsso, Turquía y los Estados Danubianos (Barcelona 1896) págs. 16-17. 
Este fragmento demuestra el desconocimiento de la existencia de la comunidad judía de Estambul por parte de la sociedad española. A diferencia de los textos anteriores, estas descripciones se alejan de los temas de interés económico o socioeconómico, centrándose en otros de tipo lingüístico: el idioma y la prensa en judeoespañol.

Otro español coetáneo que aportó su granito de arena al conocimiento de los sefardíes es el diplomático Antonio de Zayas, destinado en Estambul como secretario de tercera entre el 1 de enero de 1897 y el 30 de julio de 1898. Si bien hoy su nombre ha pasado al olvido, en su día gozó de un cierto prestigio como poeta parnasiano o modernista. Su estancia en la capital otomana produjo dos obras: una con su visión poética de la ciudad en Joyeles Bizantinos (1902) y otra con sus experiencias en A Orillas del Bósforo (1912) ${ }^{16}$. Una memoria redactada por este diplomático será precisamente una de las fuentes del doctor Pulido en Los israelitas españoles y el idioma sefardi. Parece ser que Zayas se anticipó a Pulido a la hora de desvelar el interés político y económico de los sefardíes otomanos aunque, eso sí, con bastantes diferencias:

Peligrosos o molestos tal vez como súbditos dentro del territorio español conforme lo entendieron los Reyes Católicos, serían seguramente útiles a nuestros intereses como protegidos en las regiones de Oriente ${ }^{17}$.

El carácter conservador del diplomático es patente al justificar el decreto de expulsión por «la repugnancia que por tradición, por costumbre o por rutina inspira a todo cristiano la gente de estirpe hebrea» 18.

Zayas hace hincapié en la utilización del judeoespañol como el principal vínculo entre sefardíes y españoles. De esa manera plantea un modelo similar al francés, basado en la educación y en la prensa como medio de penetración en la economía del Imperio otomano. Así, el diplomático destaca la existencia de trece escuelas de la Alianza Israelita Universal en Estambul,

16 Sobre este autor véase mi artículo «Antonio de Zayas y los sefardíes Otomanos», Raíces 62 (otoño 1997) págs. 61-64.

17 Antonio de Zayas, A Orillas del Bósforo (Madrid 1912) pág. 93.

18 ZaYAs Bósforo pág. 86. 
institución fundada en Francia en 1860 cuyo objetivo era el de la renovación de las comunidades judías orientales, las cuales mantenían en sus centros tradicionales la enseñanza en ladino. Sobre la prensa en judeoespañol Zayas cita dos periódicos en caracteres hebreos: El Tiempo y El Telégrafo. Lo cierto es que el primer periódico importante judío de Estambul, el Journal Israelite (1841-1860), se publicaba en francés, al cual seguirían en ladino y caracteres hebreos La Luź de Yisrael ('Or Yisrael) (1853) y El Jornal Yisraelit (1860-1871), llamado más tarde El Nacional (1871-1890) y después El Telégrafo (1872-1930), al que hace referencia Zayas junto con el El Tiempo (1871-1930); todos ellos coexistieron con los turcos Sarkiye (1867-) y Zaman (1872-), también en caracteres hebreos ${ }^{19}$.

Zayas afirmaba que la comunidad de Estambul estaba compuesta de unos sesenta mil miembros ${ }^{20}$, de los cuales cuarenta mil eran súbditos otomanos y el resto principalmente italianos o austriacos. De todos ellos, cincuenta y dos mil hablaban lo que denomina «la lengua de Cervantes»; aunque sólo sumaban doscientos entre protegidos y súbditos españoles. Este dato prueba la escasa importancia que en España se daba a la comunidad sefardí, sobre la cual existía ya suficiente información antes de la campaña de Pulido. Conviene recordar que la estancia de Zayas en Estambul coincide con la crisis de 1898, en la que los intereses españoles se centraban al otro lado del Atlántico o en Filipinas, es decir, en los restos de su Imperio. Para terminar con este autor veamos el siguiente fragmento que es bastante representativo de la forma de pensar de los sectores más conservadores de la sociedad española y su confusión en materias de política, economía y religión:

Poco costaría, en mi sentir, al Gobierno español generalizar entre los judíos del Imperio Otomano la lengua castellana y llevar a término feliz una hermosa obra de civilización, de progreso y de

19 Véase Stanford J. SHAw, The Jews of the Ottoman Empire and the Turkish Republic (Londres 1991) págs. 181-182; y Elena ROMERO, La creación literaria en lengua sefardi (Madrid 1992) págs. 179-219: págs. 182-183 y 190.

20 Según el censo de 1885 había 22.394 hombres y 21.947 mujeres, y según el de 1914 un total de 52.126. Standford J. SHAw, «The Population of Istanbul in the Nineteenth Century», Istanbul Üniversitesi Edebiyat Fakültesi Tarih Dergisi 32 (1979) pág. 407. 
apostolado, predicando entre la juventud israelita las verdades del Evangelio, que pondrían al amparo de nuestra bandera a una muchedumbre suficientemente considerable para aumentar la importancia política y financiera de nuestros consulados en Oriente, y para abrir, ayudados por la actividad mercantil de los hebreos, nuevos mercados a los productos de nuestro suelo y de nuestra industria naciente.

Además de tan inmensas ventajas, se obtendría la de devolver a España el papel que le corresponde por los prestigios de su historia y por las cualidades de sus hijos; y la de dar a conocer nuestra riqueza agrícola y nuestra hermosa lengua, tan ignoradas hoy en todo el mundo 21 .

El verdadero descubridor para la sociedad española de la realidad sefardí fue Ángel Pulido Fernández. La toma de contacto de este senador y médico español tuvo lugar durante su viaje por la Europa del este y Turquía en el verano de 1903, donde conoció a Enrique Bejarano, el cual le pondría en contacto con la comunidad sefardí 22 . Sobre este viaje, su hijo, Ángel Pulido Martín, publicó el libro Cartas médicas, donde narra las peripecias del trayecto; el capítulo XIII está dedicado a la capital otomana. Gracias a la influencia de Elías Pachá, vice-almirante y médico imperial, a quien habían sido encomendados por Bejarano, visitaron allí la escuela de medicina militar. El estudiante de medicina describe el encuentro con otro sefardí, un profesor de bacteriología, y la situación del hospital judío de Balat, inaugurado pocos años antes gracias, entre otras cosas, a donaciones de los banqueros Rothschild o Hirsch ${ }^{23}$. Lo que dice al final de ese capítulo está en consonancia con la postura de su padre:

Los judíos españoles de Constantinopla (Sephardim) son considerados universalmente como muy superiores a los otros de su raza que allí habitan; son más morales y más instruidos, ocupan mejor situación económica, y aún los de clase inferior muéstranse más limpios y aseados que los procedentes de otros países ${ }^{24}$.

21 ZAYAS Bósforo págs. 104-105.

22 Este tema lo he tratado en Asuero «Bejarano».

23 De este tema me ocupo en mi artículo «El Hospital de Or ha-Hayim», entregado para Raices 36 (1998).

24 Ángel Pulido Martín, Cartas médicas (Madrid 1906) pág. 148. 
Impresionado por este descubrimiento, Ángel Pulido Fernández publicó el 8 de febrero de 1904 el artículo titulado «Los judíos españoles y el idioma sefardí» en La Ilustración Española y Americana. Ese mismo año vio la luz Los israelitas españoles y el idioma castellano y en 1905 Españoles sin patria y la raza sefardí. Al igual que la mayoría de los autores, a la hora de describir las comunidades sefardíes primaron factores socioeconómicos: papel de los judíos en el alto funcionariado otomano (generales, coroneles, capitanes, médicos, farmacéuticos), en la educación y en la prensa; o intereses meramente económicos:

En el comercio otomano, los judíos españoles figuran en primera línea, y algunos son millonarios. Me decía Bejarano: Si España hubiera gestionado y estimulado la repatriación de estos judíos, yo sé de unos pocos que consigo se hubieran llevado más de mil millones de francos. No se trata de admitir gente pobre y buscona, sino gente rica y emprendedora 25.

Las obras de Pulido se basan en las opiniones de aquellos sefardíes que estaban a favor de retomar los lazos con España, basándose en la lengua y cultura hispánica como factor de cohesión. En este contexto, los corresponsales en Estambul fueron el coronel Moisés dal Medico, primer secretario intérprete de la Marina Imperial Otomana en Constantinopla, y Moisés Fresco, director de la escuela de la Alianza Israelita Universal del barrio de Gálata, escritor y periodista que estuvo al frente de El Ustad (1888-1891) 26. La correspondencia de esos dos intelectuales otomanos se centra en el estado del judeoespañol, el cual iba dejando paso al francés como lengua de educación y de cultura. Sobre el caso de Fresco merece la pena resaltar su situación: había sido educado en ladino, dirigía un colegio francés y había estado al frente de un periódico turco escrito con caracteres hebreos. Su postura es muy similar a la de otros corresponsales de Pulido, como Abraham Galante 27 o Enrique

25 Ángel Pulido Fernández, Los israelitas españoles y el idioma castellano (Madrid 1904) pág. 97.

26 SHAw Jews of the Ottoman Empire pág. 181; y Romero Creación pág. 190 e Índice onomástico.

27 Véase mi artículo «Abraham Galante», Raices 31 (1997) págs. 49-52. 
Bejarano, los cuales participaban del nacionalismo turco -Galante fue elegido diputado en 1943 y Bejarano primer Gran Rabino de la República de Turquía- a la par que eran miembros de academias francesas, españolas e italianas, o participaban en la campaña de Pulido.

El 3 de diciembre de 1904 Pulido solicitó en el Senado que se aprobase la propuesta de concesión de la nacionalidad española a los sefardíes. Una vez más, bajo una afinidad cultural y lingüística subyacían unos intereses económicos que habrían podido ser positivos para ambas partes. Se aportó la información de David Rousso, un abogado que apostaba por fortalecer las relaciones comerciales entre España y Turquía a la par que la enseñanza y la prensa en judeoespañol. Su propuesta y la nueva información de Moisés Fresco sobre la situación de los judíos de Estambul se publicaron en Españoles sin patria y la raza sefardí en 1905. El libro deja a los propios judíos que expongan su situación, lo cual les permite en cierto modo defenderse de ciertas acusaciones de autores como Gautier, d'Amicis o de la Rada, como es el tema de las condiciones higiénicas de los barrios pobres, uno de los más repetidos:

Entramos en la judería de Haskeuy ó de Balat. Que animación! que ruido! Por las calles los hombres discuten con voz alta y gestos expresivos; las mujeres se interpelan de la ventana a la calle, ó establecen conversaciones de ventana á ventana. Algunas casitas son bajas y el que pasa por la calle vé muy bien el interior. Se puede remarcar que el interior por tan pobre que sea, es muy limpio 28 .

Hasta aquí las posturas analizadas pertenecen en su mayoría al ámbito de lo «oficial», al proceder de militares, diplomáticos o políticos. Pero a principios de siglo también hay testimonios de dos cronistas independientes: Josep Pin i Soler y Vicente Blasco Ibáñez. El primero llegó a Estambul posiblemente en 1905. Uno de sus objetivos era el de rememorar las gestas de los almogávares en su apoyo a los bizantinos. Allí descubrió a los descendientes de los expulsados que lo fueron, según el autor, de una manera cruel y masiva. Al igual que

28 Ángel Pulido Fernández, Españoles sin patria ... (ed. facsímil Granada 1993) pág. 409. 
otros observadores, destaca los apellidos judíos, como García, Toledo o Castro, y la utilización del ladino definido como un castellano clarísimo con numerosos étimos procedentes del griego moderno, del francés y del italiano.

Un domingo de verano Pin i Soler conoció a dos sefardíes en uno de los vapores que surcaban el Bósforo, un tenedor de libros y el gerente de una relojería, los cuales descendían de españoles y por tales se tenían. El viajero catalán hizo amistad con ellos, que le convidaron a almorzar en una villa del Bósforo y le pidieron que transcribiera al alfabeto latino un texto sobre la expulsión, procedente del periódico El Tiempo, en el cual no se mostraba ninguna animadversión contra los españoles. Pin i Soler reproduce el artículo junto a una poesía, «La linda caxa», cuyos primeros cinco versos aparecen también en caracteres hebreos al igual que el título del periódico. Este observador quiso conocer el estado de los judíos pobres de Balat, volviendo a reincidir en la diferenciación de nivel económico entre las dos clases sociales que se suelen describir: la próspera burguesía y los barrios desfavorecidos. Así, el anteriormente floreciente barrio de Balat se había convertido en un lugar lleno de basura donde habitaban los sectores más pobres de la población y los recién llegados del norte de África, los Balcanes o Rusia. Este contacto le produjo una desconfianza y un rechazo que lógicamente no tuvo en la villa del Bósforo ${ }^{29}$.

Una actitud similar se produce en Vicente Blasco Ibáñez durante su viaje a la capital otomana en el verano de 1907. El primer encuentro con un sefardí lo tuvo en Belgrado. El viajero se muestra fascinado por su lengua, pero desencantado por el interés que el sefardí tiene en convertirlo en su cliente. En estas circunstancias, cayendo en las acusaciones tradicionales de usura y de limar las monedas de oro, afirma que le intentaron estafar y deja que sus voces entren en el texto:

Que por mis hixos que no engaño, señoreto ... Que toma la pieza que soy un buen trocador de dinero ... Que la tomes como si fuera una alahaxa ... Que por mis viejos te lo juro, que antaño

29 Sobre este tema véase mi artículo «Pin i Soler y los Sefardíes de Estambul», Raices 29 (inv. 1996-1997) págs. 51-54. 
vinieron de allá, como tu vienes agora; porque yo, señoreto, también soy espanyol 30 .

Al igual que le sucede a la mayoría de los observadores españoles, estos encuentros fascinan no sólo a los viajeros sino a los propios judíos. Blasco Ibáñez pasa por alto los intereses económicos para desvelar la importancia que tiene para los sefardíes la tierra que los expulsó. Así lo demuestra a la hora de dejar Estambul:

Y también hablaré, en una novela, del barrio de Gálata en Constantinopla, el barrio de los españoles, como lo titula la topografía popular, donde veintiochomil judíos que se apellidan Salcedo, Cobo, Hernández, Camondo, etc. emplean en el seno de la familia un castellano arcaico, que es la lengua sagrada, el medio de comunicación para liberarse de la vigilancia de los enemigos.

- ¡Ah España!, ¡La bella Sion de Occidente! Los míos, los viexos, baxaron de allá.

Los cuentos que entretienen a la familia en las noches de sábado, leyendas de enormes tesoros enterrados, tienen siempre por escenario la lejana España, país fantástico del que hablan los patriarcas a los niños con grave misterio, como hablamos nosotros de Bagdad, la de las Mil y una noches. Y en las fiestas israelitas, las viejas descuelgan los panderos y entonan con sus bocas desdentadas villancicos del siglo $\mathrm{XV}$ aprendidos por sus abuelas en Toledo que fue el París del mundo judío ${ }^{31}$.

Este fragmento sirve para acabar el retrato de la comunidad judía de Estambul a lo largo de buena parte de la Cuestión de Oriente. Predomina una postura oficialista, que en los primeros años de su descubrimiento les es contraria. Se les recuerda cuando los intereses socioeconómicos españoles les son favorables, dejando bien claro la existencia de dos clases sociales bien definidas. Las opiniones de Pin i Soler o de Blasco Ibáñez no se puede decir que les sean totalmente propicias, pero desvelan un interés en describir la forma de vida de los sefardíes y lo que para ellos representaba la tierra que abandonaron.

30 Vicente Blasco IbÁÑEz, Obras Completas (Madrid 1986) vol. II pág. 53. El tema de su estancia en la capital otomana lo he tratado en «Blasco Ibáñez en Estambul», Letras de Deusto 76 (jul.-sep. 1997) págs. 57-72.

31 Blasco IBÁÑeZ Obras Completas vol. II pág. 114. 


\section{RESUMEN}

Con las paces hispano-turcas de finales del siglo XVIII se produce un acercamiento entre ambos imperios donde los sefardíes habrían podido figurar como intermediarios. A lo largo de la Cuestión de Oriente, militares, diplomáticos y periodistas irán descubriendo con sorpresa a los sefardíes de Estambul, olvidados durante largo tiempo, y su papel en la capital otomana.

\section{SUMMARY}

At the end of the 18th century, the old spanish-turkish rivalry in the Mediterranean is over. The Spanish Empire starts a new relationship with the Ottomans discovering in this Empire a minority that could have had represented them: the sefardies. During the Eastern Question, militars, diplomats and journalists will give notices of the longtime forgotten Spanish Jews of Istanbul and their role in the Ottoman capital. 